\title{
Is Non-Chlamydial Non-Gonococcal Urethritis Associated with Significant Clinical Complications in Men? A Systematic Review
}

\author{
Cassandra E.L. Fairhead ${ }^{a, b} \quad$ Alexander Hampson ${ }^{b} \quad$ Louis Dwyer-Hemmings ${ }^{a, b}$ \\ Nikhil Vasdev ${ }^{b, c}$ \\ a University College London Medical School, London; ${ }^{b}$ East and North Hertfordshire NHS Trust, Department of Urology, Lister Hospital, \\ Stevenage; 'School of Life and Medical Sciences, University of Hertfordshire, Hatfield, UK
}

\author{
Key Words \\ Urethritis • Balanoposthitis • Epididymitis • Complication • \\ Reactive arthritis
}

\begin{abstract}
Background: It is estimated that between 50 and $89 \%$ of non-gonococcal urethritis is not caused by Chlamydia trachomatis. Associations between non-chlamydial non-gonococcal urethritis (NCNGU) with balanoposthitis, epididymo-orchitis and reactive arthritis have been suggested, but evidence to support these often-theoretical relationships is sparse and further investigation is called for. Concerns over increasing antimicrobial resistance has rendered the need for clarity over this question ever more pressing in recent years. A review of the current evidence on the complications of NCNGU in men is therefore urgently warranted. Objective: This systematic review summarizes and evaluates the available evidence that NCNGU, whether symptomatic or asymptomatic, causes the significant complications that are already well-recognized to be associated with non-gonococcal urethritis. These significant complications are epididymo-orchitis, balanoposthitis, and sexually-acquired reactive arthritis (Reiter's syndrome) including arthritis or conjunctivitis. Summary: We conducted a systematic review and qualitative synthesis using the Preferred Reporting Items for Systematic Reviews and Meta-Analysis framework. Five databases (PubMed, EMBASE, Cumulative Index to Nursing and Allied Health Literature, PsycINFO, and British Nursing Index) were searched. We included studies that measured
\end{abstract}

\section{KARGER}

Fax +4161306 1234

www.karger.com
E-Mail karger@karger.com
(C) 2020 The Author(s)

Open access

This article is licensed under the Creative Commons AttributionNonCommercial-NoDerivatives 4.0 International License (CC BYNonCommercial-NoDerivatives 4.0 International License (CC BYNC-ND) (htp.//Www.karger.com/Services/OpenAccessLicense) clinical outcome after diagnosis of NCNGU in men. Bias was assessed using variations of the Newcastle-Ottawa scale. Data were extracted and entered into a pre-written data abstraction proforma. Seven peer-review studies were included. This included 2 retrospective cohort studies, 1 case series, 2 case reports and 2 cross-sectional studies. The studies described and analyzed 3 types of complication: balanitis, posthitis and/or meatitis; reactive arthritis and/or conjunctivitis; and epididymitis. All studies reported one or more complications. Key Messages: This review identifies an important avenue for future research: while the available evidence suggests that NCNGU has the potential to cause significant complications in men, with the strongest evidence existing for balanitis, posthitis and/or meatitis, the nature and significance of these relationships is far from clear. The findings of this review suggest that prospective, adequately powered research into whether there is a causal link between NCNGU and significant clinical complications in men would be highly worthwhile. The findings of this review raise important questions about the utility of the term NCNGU in research and clinical practice.

(c) 2020 The Author(s)

Published by S. Karger AG, Basel

\section{Introduction}

It is estimated that between 50 and $89 \%$ of non-gonococcal urethritis is not caused by Chlamydia trachomatis [1]. Since its isolation in 1980, Mycoplasma genitalium 
has been increasing recognized as an important cause of non-chlamydial non-gonococcal urethritis (NCNGU) in men. Associations with balanoposthitis, epididymo-orchitis and reactive arthritis have been suggested, but evidence to support these often theoretical relationships is sparse and further investigation called for, particularly given concerns that patients positive for Mycoplasma genitalium report histories of lower genital tract pain, epididymitis and arthritis [2-6]. The need for clarity over the question of the complications of Mycoplasma genitalium and NCNGU in general has become even more pressing in recent years. Macrolide resistance in Mycoplasma genitalium has reached such a high prevalence that the British Association for Sexual Health and HIV (BASHH) has warned that within a decade the pathogen has the capacity to become a 'superbug' $[6,7]$.

In women Mycoplasma genitalium infection can cause serious complications such as pelvic inflammatory disease, and BASHH estimates that of the 3,000 cases of Mycoplasma genitalium-related pelvic inflammatory disease that occur each year in the UK approximately 90 women become infertile [8]. While screening of asymptomatic men for Mycoplasma genitalium has been shown not to be cost effective, it is speculated that testing for the pathogen in cases of symptomatic male urethritis would lead to both improved clinical outcomes and better antimicrobial stewardship [9]. In order to evidence this claim, particularly in a climate where increasing financial pressure on sexual health services leaves public health commissioners unable to follow current BASHH non-gonococcal urethritis guidelines [6], a review of the current evidence on the complications of NCNGU in men is urgently warranted.

Non-gonococcal urethritis has traditionally been distinguished from gonococcal urethritis on the bases of the absence of Gram-negative diplococci on Gram-stained microscopy. Progress in microbiological diagnosis now enables more specific testing for the causative pathogens in urethritis and nucleic acid amplification tests (NAATs) for gonorrhea and chlamydia are now favored in diagnosis. This in part has enabled NCNGU, sometimes called non-specific urethritis, to emerge as a diagnostic category. Causes of NCNGU include Mycoplasma genitalium, Ureaplasma urealyticum, Trichomonas vaginalis, adenovirus, herpes simplex virus (HSV) and in rare cases Mycoplasma hominis and Ureaplasma parvum, as well as non-infectious causes [9-11]. The aim of this systematic review is to summarize and evaluate the available evidence regarding whether NCNGU causes the significant complications that are already well-recognized to be associated with non-gonococcal urethritis. These significant complications are epididymo-orchitis, balanoposthitis, and sexually-acquired reactive arthritis (Reiter's syndrome) including arthritis or conjunctivitis.

\section{Materials and Methods}

The Preferred Reporting Items for Systematic Reviews and Meta-Analyses review protocol was used and the review was prospectively registered on PROSPERO.

\section{Study Characteristics and Eligibility Criteria}

The review included studies published after January 1993, because this was the year in which NAAT for Chlamydia trachomatis became commercially available [12], up to and including August 2018. For practical reasons the review included only studies published in English.

Participants Men identified to have either symptomatic or asymptomatic NCNGU.

Inclusion Criteria Study participants had to meet the following inclusion criteria, based on current UK best practice guidelines [1, 13, 14]: (1) Men with, upon methylene-blue or Gram-staining, either a) an anterior urethral smear demonstrating $\geq 5$ polymorphonuclear neutrophil leukocytes (PMNLs) per high power $(\times$ $1,000)$ microscopic field (averaged over 5 fields with the greatest concentration of PMNLs) or b) a spun first-pass urine or strands visually identified in a first-pass urine demonstrating $\geq 10$ PMNLs per high power $(\times 1,000)$ microscopic field (averaged over 5 fields with the greatest concentration of PMNLs). If explicitly stated, studies with a higher threshold for microscopic diagnosis were included. (2) A negative first-pass urine or urethral swab NAAT test for Chlamydia trachomatis. (3) A negative NAAT, microscopy or culture test for gonorrhea (provided that neither of the other 2 tests for gonorrhea was positive).

Exclusion Criteria Studies which did not undertake microscopy for diagnosis (for example studies which used a leukocyte esterase test to diagnose urethritis) and studies which relied on alternative techniques such as enzyme immunoassay for diagnosis of chlamydia or gonorrhoea, because of unreliable sensitivity [1, 15]. Review articles and meta-analyses were also excluded.

Study Design Studies reporting clinical outcomes for men with NCNGU, including trials, observational studies and case reports were included. No limit was placed on the length of follow-up within the studies, in order to minimize the chance of excluding potentially relevant studies identifying a long latency from infection to complications [4].

Validity The number of studies relating to the complications of NCNGU is low and therefore studies were included regardless of their validity as assessed by the researcher.

\section{Information Sources}

Five databases were searched (PubMed, EMBASE, Cumulative Index to Nursing and Allied Health Literature, PsycINFO, and British Nursing Index). These were chosen based on their accepted breadth and scope [16]. The search terms used were: "non -chlamydial"; "non-gonococcal"; "urethritis"; "NCNGU"; "epididymitis"; "orchitis"; "epididymo-orchitis"; "sexually-acquired 


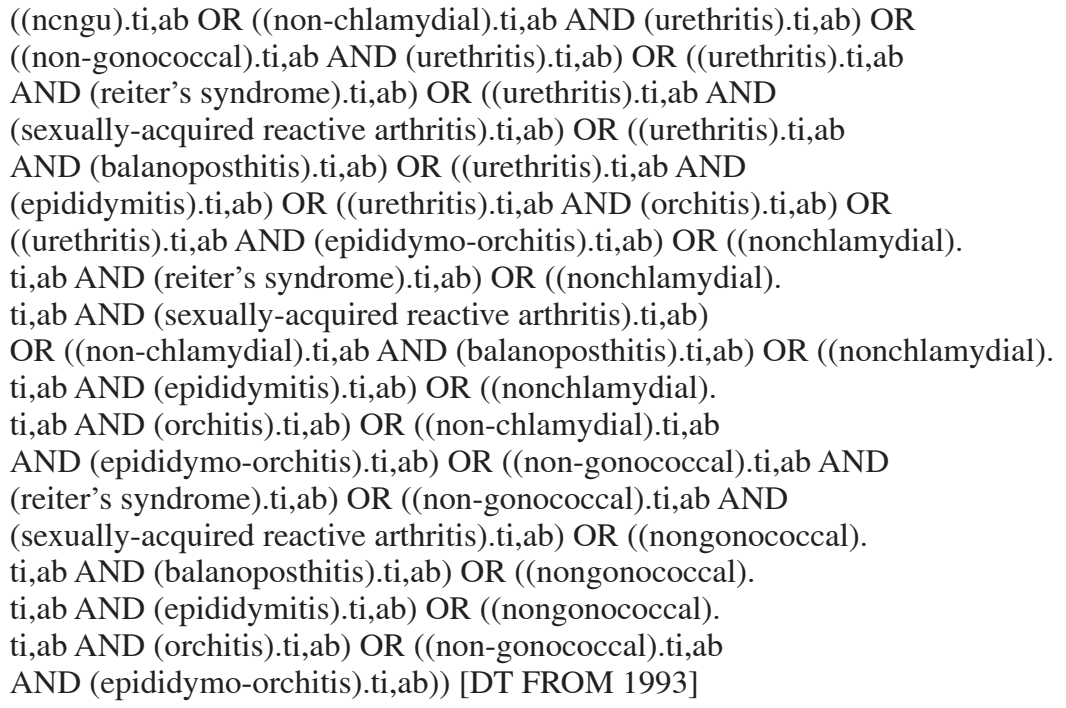

Fig. 1. Example of electronic search method.

reactive arthritis"; "Reiter's syndrome"; "balanoposthitis". The dates of coverage of these databases were 1993 to 2018, and the date last searched was $23 / 09 / 2018$. An example of the electronic search method is found in figure 1.

\section{Study Selection Process}

Titles and abstracts were compared for similarity using text comparison software [17] and duplicates excluded. The remaining records were screened by the researcher and assessed for potential relevance. A second researcher then independently assessed the records for potential relevance in order to minimize selection bias. The concordance between the 2 researchers was $86 \%$. If potential relevance was unclear from the abstract, a full text was obtained and assessed. The abstracts were then categorized as either 'for exclusion' or 'for further assessment to determine eligibility' or 'editorial or review article'. Full text articles were obtained for studies categorized as 'for further assessment to determine eligibility'. Based upon the eligibility criteria, these articles were then allocated to either 'for exclusion' or 'for inclusion'. To reduce bias, this process was undertaken by both researchers independently and any disagreements were resolved by discussion.

Finally, in order to capture articles potentially meeting the inclusion criteria but with titles and abstracts missed by the literature search, full texts were obtained for all articles categorized as either 'for inclusion' or 'editorial or review article'. Their references were then screened by both researchers, and full texts were retrieved for any references identified as potentially meeting the inclusion criteria. These texts were then categorized as either 'for inclusion' or 'for exclusion'. This categorization was conducted by both researchers independently and again any disagreements were resolved by discussion. Data were extracted by the primary researcher and entered into a pre-written data abstraction proforma.

Complications of Non-Chlamydial

Non-Gonococcal Urethritis in Men

\section{Data Items Collected and Assumptions Made}

The data items collected were study setting and design; sample size; diagnostic criterion used for NCNGU; whether participants were symptomatic or asymptomatic; significant well-recognized clinical complications of non-gonococcal urethritis reported (specifically epididymo-orchitis, sexually-acquired reactive arthritis (Reiter's syndrome) including arthritis or conjunctivitis, or balanoposthitis) and whether the sample was also identified as positive for Mycoplasma genitalium through NAAT testing. It was assumed that complications were diagnosed accurately according to accepted best medical practice.

\section{Assessing for Bias}

The quality of studies was assessed for the risk of bias. Observational studies, including cohort and case-control studies, were evaluated using the Newcastle-Ottawa Scale [18]. This scale uses a star system to assess participant selection, comparability of study groups, and ascertainment of outcomes. The following thresholds were used for scoring studies: (1) Good quality: 3 or 4 stars in selection domain AND 1 or 2 stars in comparability domain AND 2 or 3 stars in outcome/exposure domain; (2) Fair quality: 2 stars in selection domain AND 1 or 2 stars in comparability domain AND 2 or 3 stars in outcome/exposure domain; (3) Poor quality: 0 or 1 star in selection domain OR 0 star in comparability domain OR 0 or 1 star in outcome/exposure domain.

For case reports and case series, a modified version of the Newcastle-Ottowa Scale was applied. This modified scale removes items relating to comparability and adjustment and focuses on selection, representativeness of cases, exposure and ascertainment of outcomes. This modified scale has been successfully applied in several published systematic reviews [19]. For this modified scale the following thresholds were used: (1) Good quality: 1 star in selection domain, 2 stars in ascertainment domain, 3 or 4 stars in 


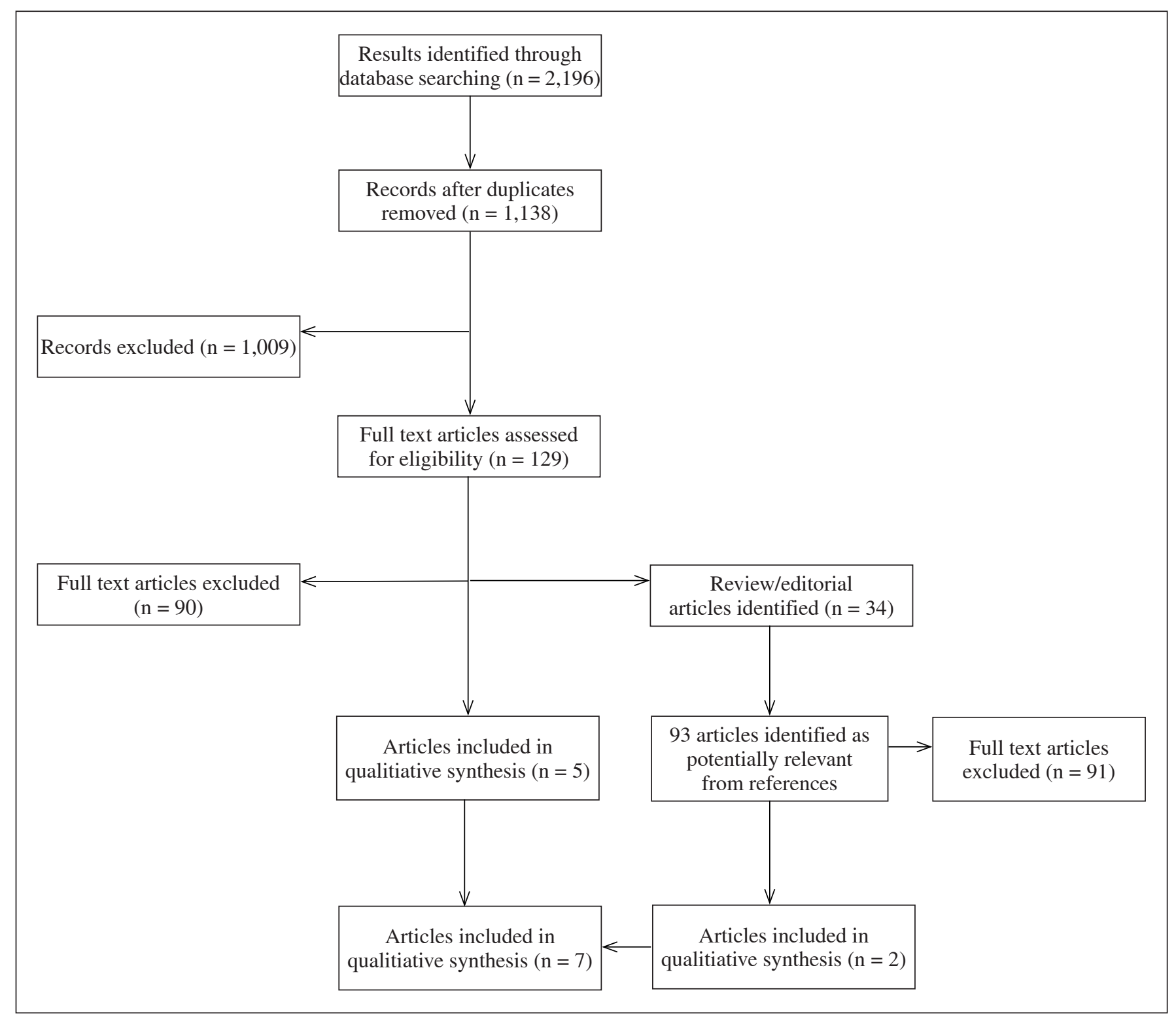

Fig. 2. Flowchart showing the study selection process.

causality domain and 1 star in reporting domain; (2) Fair quality: 1 star in the selection domain, 1 star in the ascertainment domain, 2 stars in the causality domain and 1 star in the reporting domain; (3) Poor quality: no stars in either the selection, ascertainment or reporting domain, or no or 1 star in the causality domain.

For cross-sectional studies an adapted Newcastle-Ottawa scale [20], used successfully in Herzog et al. [21] was used. The following thresholds were used: (1) Good quality: 4 or 5 stars in selection domain, 2 stars in ascertainment domain, 3 or 4 stars in outcome domain; (2) Fair quality: 3 stars in the selection domain, 1 star in the ascertainment domain, 2 stars in the outcome domain; (3) Poor quality: no, 1 or 2 stars in the selection, no stars in ascertainment domain, or no or 1 star in the outcome domain.
This information was then considered and its relevance explored in the discussion and conclusion of the systematic review. Additionally, risk of bias across studies (for example reporting and publication bias) was considered.

\section{Results}

Total 2,196 records were identified in the initial search, of which 1,058 were identified as duplicates and excluded. The titles and abstracts of the remaining 1,138 
Table 1. Pre-written data extraction

\begin{tabular}{|c|c|c|c|c|c|c|c|c|c|}
\hline Number & $\begin{array}{l}\text { Lead author } \\
\text { and date }\end{array}$ & Location & $\begin{array}{l}\text { Study } \\
\text { design }\end{array}$ & $\begin{array}{l}\text { Year(s) of } \\
\text { study }\end{array}$ & $\begin{array}{l}\text { Sample size } \\
\text { (men with } \\
\text { NCNGU) }\end{array}$ & $\begin{array}{l}\text { Diagnostic criterion } \\
\text { used for NCNGU }\end{array}$ & Symptomatic & $\begin{array}{l}\text { Complication(s) } \\
\text { reported }\end{array}$ & $\begin{array}{l}\text { Mycoplasma gen- } \\
\text { italium positively } \\
\text { identified }\end{array}$ \\
\hline 1 & $\begin{array}{l}\text { Ito et al. } \\
(2016)\end{array}$ & Gifu, Japan & cross-sectional & $\begin{array}{l}\text { April 2013- } \\
\text { July } 2015\end{array}$ & 109 & $\begin{array}{l}\geq 5 \text { leukocytes per } \\
\text { HPF }(\times 1,000) \text { in } \\
\text { their Gram-stained } \\
\text { urethral smear }\end{array}$ & yes & $\begin{array}{l}\text { balanitis: } 51 \\
\text { cases; } \\
\text { conjunctivitis: } 6 \\
\text { cases }\end{array}$ & $\begin{array}{l}22 \text { cases, of which } \\
9 \text { had balanitis } \\
\text { and none reported } \\
\text { conjunctivitis }\end{array}$ \\
\hline 2 & $\begin{array}{l}\text { Chrisment } \\
\text { et al. (2013) }\end{array}$ & $\begin{array}{l}\text { Bordeaux, } \\
\text { France }\end{array}$ & case report & March 2011 & 1 & $\begin{array}{l}\geq 5 \text { leukocytes } \\
\text { per HPF }(\times 1,000) \\
\text { per Gram-stained } \\
\text { urethral smear }\end{array}$ & yes & $\begin{array}{l}\text { reactive arthritis: } \\
1 \text { case }\end{array}$ & yes \\
\hline 3 & $\begin{array}{l}\text { Horner et } \\
\text { al. }(2011)\end{array}$ & London, UK & $\begin{array}{l}\text { retrospective } \\
\text { cohort }\end{array}$ & 1991-1993 & 56 & $\begin{array}{l}\geq 5 \text { PMNLs per } \\
\text { HPF }(\times 1,000) \text { in } \\
5 \text { or more fields } \\
\text { of a Gram-stained } \\
\text { urethral smear }\end{array}$ & yes & $\begin{array}{l}\text { balanoposthitis: } \\
12 \text { cases }\end{array}$ & $\begin{array}{l}\text { yes: Mycoplasma } \\
\text { genitalium found } \\
\text { to be significantly } \\
\text { associated with } \\
\text { balanoposthitis but } \\
\text { original figures not } \\
\text { available }\end{array}$ \\
\hline 4 & $\begin{array}{l}\text { Falk et al. } \\
\text { (2004) }\end{array}$ & $\begin{array}{l}\text { Örebro, } \\
\text { Sweden }\end{array}$ & cross-sectional & $\begin{array}{l}\text { February } 2000 \\
\text {-July } 2000\end{array}$ & 207 & $\begin{array}{l}\geq 5 \text { PMNLs per } \\
\text { HPF }(\times 1,000)\end{array}$ & yes & $\begin{array}{l}\text { epididymitis: } \\
1 \text { case }\end{array}$ & $\begin{array}{l}\text { yes: } 27 \text { cases (none } \\
\text { with epididymitis) }\end{array}$ \\
\hline 5 & $\begin{array}{l}\text { Ito et al. } \\
\text { (2017) }\end{array}$ & $\begin{array}{l}\text { Sendai, } \\
\text { Japan }\end{array}$ & case series & $\begin{array}{l}\text { April } 2013 \\
\text {-December } \\
2015\end{array}$ & 10 & $\begin{array}{l}\geq 5 \text { PMNLs per } \\
\text { HPF }(\times 1,000)\end{array}$ & yes & $\begin{array}{l}\text { balanoposthitis } \\
\text { (meatitis): } 6 \\
\text { cases }\end{array}$ & $\begin{array}{l}\text { yes: } 1 \text { of the } 6 \\
\text { cases of meatitis } \\
\text { was mixed HSV } \\
\text { and Mycoplasma } \\
\text { genitalium }\end{array}$ \\
\hline 6 & $\begin{array}{l}\text { Ong et al. } \\
\text { (2017) }\end{array}$ & $\begin{array}{l}\text { Melbourne, } \\
\text { Australia }\end{array}$ & $\begin{array}{l}\text { retrospective } \\
\text { cohort }\end{array}$ & $2000-2015$ & 80 & $\begin{array}{l}\geq 5 \text { PMNLs per } \\
\text { HPF }(\times 1,000)\end{array}$ & yes & $\begin{array}{l}\text { balanoposthitis } \\
\text { (meatitis): } 50 \\
\text { cases }\end{array}$ & no \\
\hline 7 & $\begin{array}{l}\text { Björnelius } \\
\text { et al. (2004) }\end{array}$ & $\begin{array}{l}\text { Stockholm, } \\
\text { Sweden }\end{array}$ & case report & not provided & 1 & $\begin{array}{l}\text { >30 PMNs per } \\
\operatorname{HPF}(\times 1,000)\end{array}$ & yes & $\begin{array}{l}\text { conjunctivitis: } \\
1 \text { case }\end{array}$ & $\begin{array}{l}\text { yes (PCR positive } \\
\text { for both first void } \\
\text { urine sample and } \\
\text { conjunctival swab) }\end{array}$ \\
\hline
\end{tabular}

$\mathrm{HPF}=$ High power field.

unique records were screened for potential relevance. And 129 were identified as potentially relevant original articles, and their full texts were evaluated against the inclusion and exclusion criteria. From this pool, 5 articles met the inclusion criteria and were included in the synthesis.

Total 34 potentially relevant studies were identified as review or editorial articles, and their references were screened for potential relevance. Full text articles were sought for 93 articles, and these articles were evaluated against the inclusion and exclusion criteria. Two articles from this pool met the inclusion criteria and were added to the synthesis, leaving a total of 7 articles included in the synthesis. A flowchart showed the study selection process (fig. 2). Data extraction process was summarized in table 1 [22-28].

The 7 included studies consisted of 2 retrospective cohort studies, 1 case series, 2 case reports and 2 cross-sectional studies. No prospective studies met the inclusion criteria, and no published systematic reviews were found on the topic.

The critical appraisal of each of the studies individually, utilizing variations of the Newcastle-Ottawa scale as described in the methods section, is presented in ta- ble 2. Risk of bias across studies also requires consideration: case reports and case series are included within this systematic review, and this introduces a risk of reporting bias because case reports highlighting the absence of complications are seldom published except in specific circumstances. In this review, no case reports or case series were identified that highlighted the absence of any complication. However, because the primary aim of this review is to ascertain whether NCNGU does cause significant complications, and not the incidence of these complications, this justifies inclusion of case reports and case series.

The included studies described and analysed 3 types of complication: balanitis, posthitis and/or meatitis; reactive arthritis and/or conjunctivitis; and epididymitis.

\section{Balanitis, Posthitis and/or Meatitis}

There are 4 studies analyzed balanitis, posthitis and/ or meatitis. This included 2 good quality retrospective cohort studies, 1 fair quality case series study and 1 good quality cross-sectional study. One study was performed in the UK, 1 in Australia and 2 in Japan. 
Table 2. Assessment of risk of bias [19]

Cohort

\begin{tabular}{|c|c|c|c|c|}
\hline Domain & Criterion & Score & $\begin{array}{l}\text { Study } 3 \text { (Horner et. } \\
\text { al. 2011) }\end{array}$ & $\begin{array}{l}\text { Study } 6 \text { (Ong et. al. } \\
\text { 2017) }\end{array}$ \\
\hline \multirow[t]{4}{*}{ Selection } & representativeness of the exposed cohort & $\begin{array}{l}\text { - truly representative of the average man with } \\
\text { NCNGU in the community* } \\
\text { - somewhat representative of the average man } \\
\text { with NCNGU in the community* } \\
\text { - selected group of users } \\
\text { - no description }\end{array}$ & $*$ & $*$ \\
\hline & selection of the non-exposed cohort & $\begin{array}{l}\text { - drawn from the same community as the } \\
\text { exposed cohort* } \\
\text { - drawn from a different source } \\
\text { - no description }\end{array}$ & * & $*$ \\
\hline & ascertainment of exposure & $\begin{array}{l}\text { - secure method* } \\
\text { - structured interview* } \\
\text { - written self report } \\
\text { - no description }\end{array}$ & $*$ & $*$ \\
\hline & $\begin{array}{l}\text { demonstration that the outcome of interest was } \\
\text { not present at the part of the study }\end{array}$ & $\begin{array}{l}\text { - yes* } \\
\text { - no }\end{array}$ & - & - \\
\hline Comparability & $\begin{array}{l}\text { comparability of cohorts on the basis of the } \\
\text { design or analysis }\end{array}$ & $\begin{array}{l}\text { - study controls for comorbid genito-urinary } \\
\text { infection* } \\
\text { - study controls for any additional factor* }\end{array}$ & $* *$ & $* *$ \\
\hline \multirow[t]{3}{*}{ Outcome } & assessment of outcome & $\begin{array}{l}\text { - independent blind assessment* } \\
\text { - record linkage* } \\
\text { - self-report } \\
\text { - no description }\end{array}$ & $*$ & $*$ \\
\hline & $\begin{array}{l}\text { was follow-up long enough for outcomes (the } \\
\text { pre-specified complications of male urethritis) } \\
\text { to occur }\end{array}$ & $\begin{array}{l}\cdot \text { yes* } \\
\cdot \text { no }\end{array}$ & * & - \\
\hline & adequacy of follow up of cohorts & $\begin{array}{l}\text { - complete follow-up - all subjects accounted } \\
\text { for * } \\
\text { - subjects lost unlikely to introduce bias } \\
\text { ( }<10 \% \text { loss or description of those lost) } \\
\text { - follow-up rate }>10 \% \text { and no description of } \\
\text { those lost } \\
\text { - no statement }\end{array}$ & - & $*$ \\
\hline
\end{tabular}

Case reports and case-series

\begin{tabular}{|c|c|c|c|c|}
\hline Domain & Score & $\begin{array}{l}\text { Study } 2 \text { (Chrisment } \\
\text { et. al. 2013) }\end{array}$ & $\begin{array}{l}\text { Study } 5 \text { (Ito et. al. } \\
\text { 2017) }\end{array}$ & $\begin{array}{l}\text { Study } 7 \text { (Björnelius } \\
\text { et. al. 2004) }\end{array}$ \\
\hline Selection & $\begin{array}{l}\text { - does the patient(s) represent(s) the whole } \\
\text { experience of the investigator (centre) or is } \\
\text { the selection method unclear to the extent that } \\
\text { other patients with similar presentation may not } \\
\text { have been reported?* }\end{array}$ & - & $*$ & $*$ \\
\hline Ascertainment & $\begin{array}{l}\text { - was the exposure adequately ascertained?* } \\
\text { - was the outcome adequately ascertained?*}\end{array}$ & $* *$ & $* *$ & $* *$ \\
\hline Causality & $\begin{array}{l}\text { - were other alternative causes that may explain } \\
\text { the observation ruled out?* } \\
\text { - was there a challenge/ re-challenge phenom- } \\
\text { enon?* } \\
\text { - was there a dose-response effect?* } \\
\text { - was follow-up long enough for outcomes to } \\
\text { occur?* }\end{array}$ & $* *$ & $* *$ & $*$ \\
\hline Reporting & $\begin{array}{l}\text { - is the case(s) described with sufficient details } \\
\text { to allow other investigators to replicate the } \\
\text { research or to allow practitioners make infer- } \\
\text { ences related to their own practice?* }\end{array}$ & $*$ & $*$ & $*$ \\
\hline
\end{tabular}

Cross sectional

\begin{tabular}{|c|c|c|c|c|}
\hline Domain & Criterion & Score & $\begin{array}{l}\text { Study } 1 \text { (Ito et. al. } \\
\text { (2016) }\end{array}$ & $\begin{array}{l}\text { Study } 4 \text { (Falk et. } \\
\text { al. 2004) }\end{array}$ \\
\hline Selection & representativeness of the sample & $\begin{array}{l}\text { - truly representative of the average man with } \\
\text { NCNGU in the community (all subjects or } \\
\text { random sampling)* } \\
\text { - somewhat representative of the average man } \\
\text { with NCNGU in the community (non-random } \\
\text { sampling)* } \\
\text { - selected group of users } \\
\text { - no description }\end{array}$ & $*$ & * \\
\hline
\end{tabular}




\begin{tabular}{|c|c|c|c|c|}
\hline & sample size & $\begin{array}{l}\text { - justified and satisfactory* } \\
\text { - not justified }\end{array}$ & - & - \\
\hline & non-respondents & $\begin{array}{l}\text { - comparability between respondents and non } \\
\text {-respondents is established, and the response } \\
\text { rate is satisfactory* } \\
\text { - the response rate is unsatisfactory, or compa- } \\
\text { rability between respondents and non-respon- } \\
\text { dents is unsatisfactory } \\
\text { - no description of the response rate or the } \\
\text { characteristics of the responders and the } \\
\text { non-responders }\end{array}$ & $*$ & $*$ \\
\hline & ascertainment of the exposure (NCNGU) & $\begin{array}{l}\text { - validated measurement tool** } \\
\text { - non-validated measurement tool, but the tool } \\
\text { is available or described* } \\
\text { - no description of the measurement tool }\end{array}$ & $* *$ & ** \\
\hline Comparability & $\begin{array}{l}\text { are subjects in different outcome groups are } \\
\text { comparable, based on the study design or anal- } \\
\text { ysis, and are confounding factors controlled }\end{array}$ & $\begin{array}{l}\text { - the study controls for comorbid genitouri- } \\
\text { nary infection* } \\
\text { - study controls for any additional factor* }\end{array}$ & $* *$ & ** \\
\hline \multirow[t]{2}{*}{ Outcome } & assessment of outcome & $\begin{array}{l}\text { - independent blind assessment** } \\
\text { - record linkage** } \\
\text { - self-report* } \\
\text { - no description }\end{array}$ & $* *$ & $* *$ \\
\hline & statistical test & $\begin{array}{l}\text { - the statistical test used to analyse the data } \\
\text { is clearly described and appropriate, and the } \\
\text { measurement of the association is presented, } \\
\text { including confidence intervals and p value* } \\
\text { - the statistical test is not appropriate, not } \\
\text { described or incomplete }\end{array}$ & $*$ & - \\
\hline
\end{tabular}

Case-control

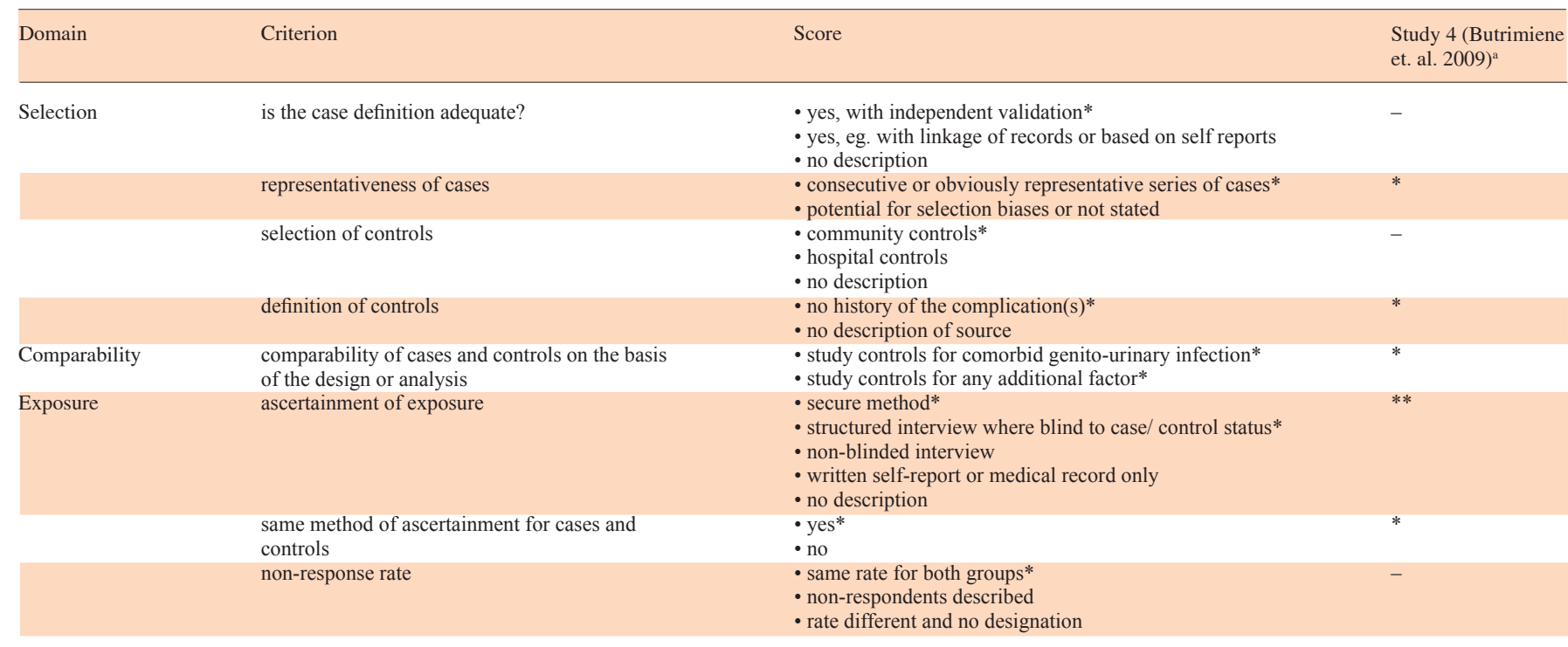

a Did not meet criteria for inclusion in final analysis; *Refers to the number of points received in that category by the paper. The number of stars is the score ( 1 to 2 , shown as *,**) for that criterion on the modified Ottowa-Newcastle bias scale.

Ito et al. [22] presented a fair quality cross-sectional study of men presenting to a urology clinic with urethritis symptoms. Urethral swabs were analyzed for Chlamydia trachomatis, Neisseria gonorrhoea, human adenovirus, Haemophilus influenzae, HSV 1 and 2, Mycoplasma genitalium and Ureaplasma urealyticum. Data on complications was presented only where men were identified to have monomicrobial NCNGU, or where no causative organism was found. Total 109 cases of NCNGU were identified, and 51/109 had evidence of balanitis on genital examination at the time of presentation. The rates broken down by causative organism were Mycoplasma genitalium 9/22, Ureaplasma urealyticum 6/14, Haemophilus influenzae 3/21, human adenovirus $11 / 12$, HSV 7/11, no organism identified 15/29.

The 2 good quality retrospective cohort studies both compared the clinical course of NCNGU with chlamydial NGU. However, they cannot be compared because 
while Horner et al. [24] excluded participants with HSV PCR-positive NCNGU, Ong et al. [27] included only men with HSV PCR-positive NCNGU.

Horner et al. [24] studied 114 men with NGU, of which they identified 56 men as having NCNGU and 12/56 (21\%) were diagnosed with "balanitis and/or posthitis" (defined as erythema of the glans and/or prepuce on genital examination at the time of presentation). The men underwent further testing for Ureaplasma urealyticum and Mycoplasma genitalium. The report does not provide a breakdown of data on which men with mycoplasma or ureaplasma were negative for chlamydia. Therefore, it is not possible to make conclusions about the capacity for either Ureaplasma urealyticum or Mycoplasma genitalium alone to cause balanitis and/or posthitis. However, the study does report that while the presence of Ureaplasma urealyticum (in men with and without chlamydia) did not increase the risk of balanitis and/or posthitis (odds ratio $=1$; CI 0.28-3.23), the presence of Mycoplasma genitalium did (odds ratio $=4.12$; CI 1.29-13.38). Furthermore, when the authors controlled for the presence of discharge, which could itself potentially cause or contribute to balantitis/posthitis, they found that Mycoplasma genitalium presence continued to be associated with balanitis and/or posthitis (odds ratio $=4.1$, CI 1.2-13.5). Total 86/114 were followed-up between 10 and 90 days after initial presentation, after receiving either 13 days of doxycycline or 14 days of erythromycin. At follow-up examination, 2 men who had originally been positive for Mycoplasma genitalium had balanitis and/or posthitis. One of these men had not had balanitis and/or posthitis originally. Both were Mycoplasma genitalium-negative at follow-up. However, no data is available on whether these men were also positive for Chlamydia trachomatis therefore they cannot be described as cases of NCNGU.

Ong et al. [27] included 80 men with HSV (25 HSV1 and 55 HSV-2). Men co-infected with Mycoplasma genitalium were excluded. The study found that men with HSV were more likely to have meatitis than those with Chlamydia trachomatis $[50 / 80(62 \%$, CI 52-72) vs. 17/80 (23\%, CI 14-32), $\mathrm{p}<0.01]$.

Ito et al. [26] presented a fair quality case series reporting 10 cases of HSV PCR-positive NCNGU. It was unknown whether these cases of HSV urethritis represented first-episode or recurrent (reactivation) HSV infection. Of these 10 men, 6 had meatitis on genital examination. Eight of the 10 men were followed-up 7-19 days later, after receiving empirical treatment for urethritis (either 7 days of $100 \mathrm{mg}$ sitafloxacin twice daily or with a singledose regimen of $2 \mathrm{~g}$ extended-released azithromycin). At this follow-up visit, men were re-tested for HSV and underwent repeat genial examinations. Two men were still positive for HSV. On genital examination, 1 of the 8 men had ongoing meatitis, despite a negative test for HSV.

\section{Reactive Arthritis and/or Conjunctivitis}

Three studies analyzed reactive arthritis and/or conjunctivitis. This included 1 fair quality cross-sectional study and 2 poor quality case reports. One study was performed in Japan, 1 in France and 1 in Sweden.

Ito et al. [22] described in the previous section, assessed men with NCNGU for self-reported conjunctivitis symptoms ("pink or red color in the whites of the eyes; increased tearing; discharge of pus"). The presence of self-reported symptoms of conjunctivitis was assessed in the 109 included men with monomicrobial NCNGU. Conjunctivitis was identified only in men with viral urethritis (human adenovirus 1/11; HSV 5/12). None of the men positive for solely Mycoplasma genitalium, Ureaplasma urealyticum or Haemophilus influenzae, or those with no organism identified, reported conjunctivitis.

Both case reports described cases of inflammatory reactions (reactive arthritis and conjunctivitis) in young men and attributed them to Mycoplasma genitalium. Chrisment et al. [23] reported a case of reactive arthritis complicating Mycoplasma genitalium urethritis in an HLA-B27-positive 29-year-old man. During the disease course the patient's clinical presentation included genital lesions, urethritis, inguinal lymphadenopathy, perianal intertrigo, oral aphthous ulcers, and oligoarthritis, but no conjunctivitis. Biochemical tests revealed a raised C-reactive protein, raised white blood cell count and HLA-B27 positivity, but the patient tested negative for a range of rheumatological and viral causes of this presentation and negative for chlamydia and gonorrhea. Antimycosis treatment, NSAIDS, amoxicillin/clavulanate, and doxycycline and ceftriaxone failed to improve the patient's clinical condition. Following this, Mycoplasma genitalium was detected with PCR in 2 urine samples. The patient was then treated with $400 \mathrm{mg}$ of moxifloxacin daily for 10 days, with the aim of treating the Mycoplasma genitalium. Four days after completing this course he failed to improve and methotrexate therapy was initiated. This was continued for 7 weeks at which point the patient's clinical condition had improved significantly. Although Mycoplasma genitalium was not obtained from synovial fluid aspirated, at the time of the aspiration the patient has already received 6 days of moxifloxacin, which may have impacted this detection. 
Björnelius et al. [28] reported the case of a 22-yearold white, otherwise healthy man with a 5-month history of unilateral eye irritation and a several month history of urethritis symptoms. He had failed treatment for allergic conjunctivitis but had received no antibiotics during this period. A conjunctival swab and urine specimens were positive for Mycoplasma genitalium DNA on PCR, but negative for Chlamydia trachomatis and Neisseria gonorrhoea. He received doxycycline for 10 days. Six weeks after initiation of treatment clinical signs and symptoms diminished and conjunctival samples tested negative for Mycoplasma genitalium. Nine weeks after initiation of treatment clinical signs and symptoms had resolved completely and a first void urine sample also tested negative for Mycoplasma genitalium. The sequence of the strain of Mycoplasma genitalium found in the urine samples was found to be identical to the sequence obtained from the conjunctival specimen, strengthening the hypothesis that Mycoplasma genitalium was the causative agent in the conjunctivitis.

\section{Epididymitis}

One good quality cross-sectional study to analyze epididymitis was performed in Sweden [25]. This study compared the prevalence and clinical features of Mycoplasma genitalium and Chlamydia trachomatis infections in men attending an STD clinic. Men were tested for Mycoplasma genitalium, Neisseria gonorrhoea and Chlamydia trachomatis. The only complication assessed for was symptoms of epididymitis. Total 207 men were identified as having either only Mycoplasma genitalium or all negative tests and 1 man was identified as having symptoms of epididymitis. In this patient Mycoplasma genitalium was detected with PCR using primers detecting the Mycoplasma genitalium 16S rRNA gene, however confirmation of this result with a PCR detecting the $\mathrm{MgPa}$ adhesin gene (the same locus as that used to diagnose Mycoplasma genitalium in Chrisment et al. [23]) in accordance with the study's protocol failed, and thus the man was classed as having all negative tests.

\section{Discussion}

This review identifies and summarizes the available evidence on whether NCNGU is associated with significant clinical complications in men. The breadth in inclusion criteria enabled studies with a diverse range of methodologies and variables to be incorporated in this analysis. As such, there was substantial heterogeneity in

Complications of Non-Chlamydial

Non-Gonococcal Urethritis in Men the eligibility criteria specified within the studies, especially with respect to which etiologies of urethritis were included or excluded. This is most clearly demonstrated by the decision by Horner et al. [24] to include men positive for Mycoplasma genitalium but exclude men positive for HSV, in contrast to the decision by Ong et al. [27] to include only men positive for HSV and exclude men positive for Mycoplasma genitalium. As is discussed in the conclusion, this diversity in the eligibility criteria is a significant limitation to the external validity of the available evidence on this topic. A further general limitation to the ability to draw clear conclusions is that no prospective studies met the inclusion criteria for this review. Well-designed prospective studies can provide evidence of temporality, dose-response, specificity and statistical strength of association, all of which can provide evidence of a causal relationship between variables [29]. Furthermore, prospective cohort studies are regarded as the strongest evidence for assessing symptom prevalence, including complications [30].

The results of the included studies do consistently indicate that an association between urethritis and balanitis, posthitis and/or meatitis exists. Unfortunately, conclusions cannot be drawn about whether this relationship is causal. This owes largely to the fact that both retrospective cohort studies as well as the cross-sectional study measured the presence of balanitis, posthitis and/or meatitis at the time of presentation. Therefore, no conclusions about the temporal relationship between urethritis and the complications can be drawn. Additionally, no studies looked at dose-response relationships between the causative organisms and the development of complications.

Only one study [27] could show a causative relationship between NCNGU (specifically HSV) and meatitis on the grounds of men having a higher relative risk of meatitis when compared to men with chlamydia. However, although this study is classed as good quality according to the Newcastle-Ottawa scale, there is a significant limitation to the validity of the study's meatitis results specifically. Testing for HSV was performed when the clinician suspected a viral cause of urethritis, rather than in all men. The clinic's guidelines recommend suspecting and testing for a viral cause of urethritis (such as HSV or adenovirus) where there is "meatitis and severe dysuria with or without conjunctivitis". Therefore, men with HSV but no meatitis may have forgone an HSV test. This has the potential to significantly bias the results of the study relating to meatitis.

Ito et al. [22] present an association between viral urethritis (specifically adenovirus and HSV) and conjunc- 
tivitis. Both adenovirus and HSV are well-established causes of viral conjunctivitis, with adenovirus being the most common cause of viral conjunctivitis [31]. Chlamydia trachomatis is known to cause conjunctivitis through autoinoculation via the hands, which adds biological plausibility to the claim that the same could be true of other causes of urethritis [32]. However, there is an important distinction between viral infectious conjunctivitis, such as that known to be caused by HSV and adenovirus, and conjunctivitis seen as part of the spectrum of reactive arthritis. While the latter can be seen as an established clinical complication of urethritis, the former is best seen as a coexisting infective condition $[9,31]$. Ito et al. [22] did not test conjunctival swabs for adenovirus or HSV, and in conducting a cross-sectional study they were unable to assess for the temporal relationship between the urethritis and conjunctivitis, so it is difficult to conclude that the conjunctivitis was infective rather than reactive. Therefore, while this paper provides compelling evidence that viral urethritis is associated with conjunctivitis it adds little evidence to the theory that viral urethritis causes the clinical complication of reactive arthritis. It is also interesting that none of the 86 cases of non-viral NCNGU were found to be associated with conjunctivitis in this study.

The 2 case reports discussing reactive arthritis and/or conjunctivitis provide interesting and important insights. These studies derive significant value on the grounds of the biological plausibility of the associations described and by analogies to other known causes of reactive arthritis and conjunctivitis, such as Chlamydia trachomatis. However, there are important considerations regarding the specificity of the results that limit conclusions drawn about a causative link between NCNGU and reactive arthritis and/or conjunctivitis. Major limitations to Björnelius et al. [28] are that potential alternative causes that may explain the conjunctivitis were not adequately ruled out. As Ito et al. [22] find, adenovirus and HSV are potential causes of conjunctivitis and urethritis and neither were tested for in this case report.

In support of their diagnosis of a case of reactive arthritis caused by Mycoplasma genitalium, Chrisment et al. [23] 2013 adequately exclude an array of competing diagnoses. It remains difficult to rule out a competing diagnosis to Mycoplasma genitalium-induced reactive arthritis, such as an enteric pathogen, or a seronegative idiopathic arthritis, particularly because although the patient's clinical condition began to improve within the month after Mycoplasma genitalium was appropriately treated (though eradication of Mycoplasma genitalium from the urethra was not confirmed following treatment). This coincided with introduction of methotrexate, bringing into question any causal link between Mycoplasma genitalium eradication and resolution of the reactive arthritis. However, this does not necessarily invalidate the conclusion of a causal link because typically infections are regarded as triggering rather than sustaining agents in reactive arthritis [33]. It is also important to note that Chrisment et al. [23] report a case where the patient was HLA-B27 positive, which potentially limits the relevance of this report to the wider population of men with NCNGU.

A fair quality case-control study aiming to identify potential triggering infections for sexually-acquired reactive arthritis in both men and women compared urogenital tract inflammation and infection in 120 reactive arthritis patients with 2 control groups. The first control group consisted of 85 patients with other arthritides, and the second control group was 52 healthy persons. Differential data for men and women were not provided. All reactive arthritis patients experienced urogenital symptoms within a month before developing arthritis. The study, conducted in Vilnius, Lithuania, identified 3 cases of reactive arthritis in patients with Mycoplasma genitalium infection. No data was provided on whether these patients were co-infected with Chlamydia trachomatis (a known cause of reactive arthritis). A critical appraisal of this paper using the Newcastle-Ottawa Scale is provided in table 2. A further case series exists which does identify Mycoplasma genitalium in the joints of patients with arthritis, but it failed to meet this review's inclusion criteria for urethritis [34].The data suggesting a possible link between NCNGU and reactive arthritis is so far limited and this observation suggests that further research in this area would be highly worthwhile. In his review of current knowledge on Mycoplasma genitalium, Taylor-Robinson [5] argues that an etiological role of Mycoplasma genitalium in epididymo-orchitis seems likely by analogy with Chlamydia trachomatis. He recommends examining epididymal aspirates for the microbe as the optimal way to investigate such a role.

Very limited evidence was found addressing the question of whether NCNGU causes epididymo-orchitis. Only one cross-sectional study [25] was found reacting to this topic, and while it was good quality the presence of epididymitis was not a primary outcome measure. The study design limits any conclusions about causation, and also introduces the possibility that cases of complications could have been missed: though patients were asked to re-attend for a follow-up visit 4-5 weeks after commenc- 
ing antibiotic treatment, no information is given as to whether any complications were assessed for at the follow-up appointment, including epididymitis. Thus, a significant limitation of this study is that no conclusions can be drawn about the development of complications with time. This study does, however, suggest at least a possible relationship between NCNGU and epididymo-orchitis and the absence of other relevant studies indicates a significant gap in the literature on this topic.

A number of studies that failed to meet the inclusion criteria for this review analyze the potential etiological agents for urethritis to cause epididymitis. Ito et al. [22] in their study of 56 young men with acute epididymitis, identified 25 men with co-existing NCNGU who were also negative for Gram-negative bacilli (which would indicate a urinary tract infection rather than urethritis as the cause of the epididymitis). In these 25 men, Mycoplasma genitalium or Ureaplasma urealyticum was detected in 1 man each (4.0\%), and Mycoplasma hominis and/or Ureaplasma parvum was detected in 5 (20.0\%). This study, while both interesting and relevant for the evidence it provides towards NCNGU being a potential cause of epididymitis, could not be included in this review because it failed to adequately exclude gonorrhea as a cause of the symptoms (the diagnostic tool used was culture only rather than NAAT) and because first void urine samples rather than urethral smears were used to identify cases of urethritis. Similarly, Hoosen et al. [35] investigated the etiology of acute epididymitis in a community in Durban, South Africa. Of the 144 men identified to have acute epididymitis, data were not extractable for how many of these men met the criteria for NCNGU. However, it is possible to extract that 9 men positive Ureaplasma urealyticum met the criteria for NCNGU. This is a very interesting finding. However, this paper could not be included in the review because microscopy and detection of Chlamydia trachomatis antigen by direct immunofluorescence, rather than NAAT testing, was used as the diagnostic criterion for chlamydia, and the threshold used was 4 rather than 5 or more PMNLs per high power $(\times 1,000)$ microscopic field [35]. Finally, a randomized controlled trial into competing antibiotic treatments for acute epididymitis in men over 40 years old also found that of 172 men diagnosed with acute epididymitis 3 tested positive for Mycoplasma hominis, 3 for Mycoplasma genitalium, and 24 for ureaplasma. This study failed to meet the inclusion criteria for diagnosis of urethritis, however, and data were not available for whether these patients were coinfected with other organisms including chlamydia, gonorrhea, or urinary tract

Complications of Non-Chlamydial

Non-Gonococcal Urethritis in Men infection-causing pathogens [36]. The latter is a particularly important limitation because it is possible that these men did not have urethritis and instead had a urinary tract infection, a condition of which ureaplasma is thought to be a cause [37].

The findings of this review also offer important insights relating to the utility of the terminology used in both research and clinical practice. The diversity in the eligibility criteria in terms of causative organism in the studies is a significant limitation to the external validity of the available evidence on this topic. In order to make meaningful assessments of the risk of complications for individuals with urethritis, standardized disease entities such as NCNGU must be agreed, defined and utilized in research and in clinical practice. The global nature of this issue, as evidenced by the range in settings of the studies included in this review, is both a motivation and a challenge to this endeavor. The studies included in this review frequently allude to differences in the complications of NCNGU when broken down by causative organism, though there is insufficient data to synthesize these effects. These observations bring in to question the utility of the term NCNGU, a composite disease entity with substantial heterogeneity in how it is defined and interpreted. This adds evidence to the view that, where available, tests for potential causative organisms in urethritis should be employed in research and in the clinic.

\section{Conclusion}

This review has found that there is substantial evidence of an association between NCNGU and balanitis, posthitis and/or meatitis. The importance of this finding extends beyond the significant burden of morbidity for the men it affects: inflammation of the foreskin has been identified as a cofactor for HIV transmission [24]. It is established that sexually transmitted infections can have the potential to facilitate the transmission if HIV, and this finding is particularly pertinent given that Mycoplasma genitalium has recently been associated with HIV infection [38-40]. As Horner et al. [24] discuss, Mycoplasma genitalium is common in at least 2 populations at high risk of HIV: in men who have sex with men $(6.6 \%)$ and in men with urethritis in sub-Saharan Africa [39-41].

Prospective, adequately powered research is urgently warranted to establish whether there is a causal link between NCNGU and significant clinical complications in men. The findings from this review indicate that in conducting such research it would be beneficial to further 
stratify NCNGU cases by causative agent. This could also include investigating cases of co-infection by these organisms of chlamydial or gonococcal urethritis, or multi-microbial NCNGU, because (as noted by Ito et al. [26]), organisms which cause NCNGU may have the potential to modulate the disease course of urethritis caused by other agents. This could include modulating the incidence of complications.

\section{Acknowledgement}

I would like to express my very great appreciation to the authors of and contributors to the original works included within this review. I am particularly grateful to the patients who were involved in these original studies. I would also like to offer my special thanks to the library staff at Lister Hospital, Stevenage, for their invaluable advice regarding data sources and search strategies.

\section{References}

-1 Horner P, Blee K, O’Mahony C, Muir P, Evans C, Radcliffe K: 2015 UK National Guideline on the management of non-gonococcal urethritis. Int J STD AIDS 2016;27:85-96.

-2 Anagrius C, Lore B: Chlamydia-like symptoms can have another etiology. Mycoplasma genitalium-an important and common sexually transmitted disease. Lakartidningen 2002;99:4854-4855, 4858-4859.

-3 Taylor-Robinson D, Jensen JS: Mycoplasma genitalium: from Chrysalis to multicolored butterfly. Clin Microbiol Rev 2011;24:498514.

4 Horner PJ, Martin DH: Mycoplasma genitalium infection in men. J Infect Dis 2017; 216(suppl 2):S396-405.

-5 Taylor-Robinson D:Mycoplasmagenitaliuman up-date. Int J STD AIDS 2002;13:145-151.

6 The British Association of Sexual Health and HIV: BASHH launches new NICE accredited guidelines to help prevent Mycoplasma genitalium becoming the next superbug, but funding cuts may hinder implementation. Available from: https://www.bashh.org/news/news/ bashh-launches-new-nice-accredited-guidelines-to-help-prevent-mycoplasma-genitalium-becoming-the-next-superbug-but-funding-cuts-may-hinder-implementation/.

7 Pond MJ, Nori AV, Witney AA, Lopeman RC, Butcher PD, Sadiq ST: High prevalence of antibiotic-resistant Mycoplasma genitalium in nongonococcal urethritis. Clin Infect Dis 2014;58:631-637.

8 Kirby T: Mycoplasma genitalium: a potential new superbug. Lancet Infect Dis 2018;18: 951-952.

9 The National Institute for Health and Care Excellence: Urethritis- male. Clinical knowledge summaries, NICE, 2018 Oct. Available from: https://cks.nice.org.uk/urethritis-male.

-10 Matsuda T, Takeuchi H, Yoshida O: Ureaplasma urealyticum and mycoplasma hominis in male urethritis. Hinyokika Kiyo 1991; 37:1293-1297.

-11 Cox C, McKenna JP, Watt AP, Coyle PV: Ureaplasma parvum and Mycoplasma genitalium are found to be significantly associated with microscopy-confirmed urethritis in a routine genitourinary medicine setting. Int $\mathrm{J}$ STD AIDS 2016;27:861-867.
12 Centers for Disease Control and Prevention: Recommendations for the prevention and management of chlamydia trachomatis infections, 1993. Morbidity and Mortality Weekly Report, Centers for Disease Control and Prevention, 1993. Available from: https://www.cdc.gov/ mmwr/preview/mmwrhtml/00021622.htm.

13 Dragovic B, Patel S, Tong CYW, Barker G, Radcliffe K: 2015 UK national guideline for the management of infection with Chlamydia trachomatis. Int J STD AIDS 2016;27:251267.

14 Bignell C, Fitzgerald M: UK national guideline for the management of gonorrhoea in adults, 2011. Int J STD AIDS 2011;22:541547.

15 Estcourt C, Sutcliffe L, Mercer CH, Copas A, Saunders J, Roberts TE, Fuller SS, Jackson LJ, Sutton AJ, White PJ, Birger R, Rait G, Johnson A, Hart G, Muniina P, Cassell J: Impact of different clinical approaches to sexually transmitted infection testing in men: a systematic review, case-control study and modelling study with an economic evaluation. In: The Ballseye programme: a mixed-methods programme of research in traditional sexual health and alternative community settings to improve the sexual health of men in the UK. Southampton, UK, NIHR Journals Library, 2016. Available from: https://www. ncbi.nlm.nih.gov/books/NBK401910/ doi: 10.3310/pgfar04200.

16 Duke University: Systematic reviews: the process: databases and grey literature. Duke University Medical Centre Library \& Archives, 2018. Available from: https://guides. mclibrary.duke.edu/sysreview/databases.

17 Copyleaks: Compare two documents. 2018, Available from: https://copyleaks.com/compare.

18 Wells GA, Shea B, O'Connell D, Peterson J, Welch V, Losos M, Tugwell P: The Newcastle-Ottawa Scale (NOS) for assessing the quality of nonrandomised studies in meta-analysis. The Ottawa Hospital Research Institute, Clinical Epidemiology. Available from: http://www.ohri.ca/programs/clinical_ epidemiology/oxford.asp.
19 Murad MH, Sultan S, Haffar S, Bazerbachi F: Methodological quality and synthesis of case series and case reports. BMJ Evid Based Med 2018;23:60-63.

20 Modesti PA, Reboldi G, Cappuccio FP, Agyemang C, Remuzzi G, Rapi S, Perruolo E, Parati G: Panethnic differences in blood pressure in Europe: a systematic review and meta-analysis. PLoS One 2016;11:e0147601.

21 Herzog R, Álvarez-Pasquin MJ, Díaz C, Del Barrio JL, Estrada JM, Gil A: Are healthcare workers' intentions to vaccinate related to their knowledge, beliefs and attitudes? a systematic review. BMC Public Health 2013;13: 154.

22 Ito S, Hanaoka N, Shimuta K, Seike K, Tsuchiya T, Yasuda M, Yokoi S, Nakano M, Ohnishi M, Deguchi T: Male non-gonococcal urethritis: from microbiological etiologies to demographic and clinical features. Int J Urol 2016;23:325-331.

-23 Chrisment D, Machelart I, Wirth G, Lazaro E, Greib C, Pellegrin JL, Bébéar C, Peuchant $\mathrm{O}$ : Reactive arthritis associated with $\mathrm{Mycop}$ lasma genitalium urethritis. Diagn Microbiol Infect Dis 2013;77:278-279.

24 Horner PJ, Taylor-Robinson D: Association of Mycoplasma genitalium with balanoposthitis in men with non-gonococcal urethritis. Sex Transm Infect 2011;87:38-40.

25 Falk L, Fredlund H, Jensen JS: Symptomatic urethritis is more prevalent in men infected with Mycoplasma genitalium than with Chlamydia trachomatis. Sex Transm Infect. 2004;80:289293.

26 Ito S, Yasuda M, Kondo H, Yamada Y, Nakane K, Mizutani K, Tsuchiya T, Yokoi S, Nakano M, Deguchi T: Clinical courses of herpes simplex virus-induced urethritis in men. J Infect Chemother 2017;23:717-719.

27 Ong J, Morton AN, Henzell HR, Berzins K, Druce J, Fairle CK, Bradshaw CS, Read TR, Hocking JS, Chen MY: Clinical characteristics of herpes simplex virus urethritis compared with Chlamydial urethritis among men. Sex Transm Dis 2017;44:121-125.

-28 Björnelius E, Jensen JS, Lidbrink P: Conjunctivitis associated with Mycoplasma genitalium infection. Clin Infect Dis 2004;39:e67e69. 
29 Hill AB: The environment and disease: association or causation? Proc R Soc Med 1965; 58:295-300.

30 Centre for Evidence-Based Medicine: Levels of Evidence. Oxford Centre for Evidence-Based Medicine, 2009. Available from: https://www.cebm.net/2009/06/oxford-centre-evidence-based-medicine-levels-evidence-march-2009/.

31 The National Institute for Health and Care Excellence: Conjunctivitis-infective. Clinical Knowledge Summaries, NICE, 2018. Available from: https://cks.nice.org.uk/conjunctivitis-infective\#!backgroundsub:2.

32 Ronnerstam R, Persson K, Hansson H, Renmarker K: Prevalence of chlamydial eye infection in patients attending an eye clinic, a VD clinic, and in healthy persons. Br J Ophthalmol 1985;69:385-388.
33 Schmitt SK: Reactive Arthritis. Infect Dis Clin North Am 2017;31:265-277.

-34 Taylor-Robinson D, Gilroy CB, Horowitz S. Horowitz J: Mycoplasma genitalium in the joints of two patients with arthritis. Eur J Clin Microbiol Infect Dis1994;13:1066-1069.

35 Hoosen AA, O'Farrell N, van den Ende J: Microbiology of acute epididymitis in a developing community. Genitourin Med 1993;69: 361-363.

36 Eickhoff JH, Frimodt-Moller N, Walter S, Frimodt-Moller C: A double-blind, randomized, controlled multicentre study to compare the efficacy of ciprofloxacin and pivampicillin as oral therapy for epididymitis in men over 40 years of age. BJU Int 1999;84:827-834.

37 Reyes L, Reinhard M, Brown MB: Different inflammatory responses are associated with Ureaplasma parvum-induced UTI and urolith formation. BMC Infect Dis 2009;9:9.
38 Johnson LF, Lewis DA: The effect of genital tract infections on HIV-1 shedding in the genital tract: a systematic review and meta-analysis. Sex Transm Dis 2008;35:946-959.

39 Soni S, Alexander S, Verlander N, Saunders P, Richardson D, Fisher M, Ison C: The prevalence of urethral and rectal Mycoplasma genitalium and its associations in men who have sex with men attending a genitourinary medicine clinic. Sex Transm Infect 2010;86:21-24.

40 Napierala Mavedzenge S, Weiss HA: Association of Mycoplasma genitalium and HIV infection: a systematic review and meta-analysis. AIDS 2009;23:611-620.

41 Health Protection Agency: Sexually transmitted infections and men who have sex with men in the UK: 2008 report. http:// www.hpa.org.uk/web/HPAwebFile/HPAweb_C/1227515298225. 